Pediat. Res. 4: 129-134 (1970)

Cortisol hormones

fetus placenta

\title{
Fetal and Maternal Secretion Rate of Cortisol in Sheep: Diffusion Resistance of the Placenta
}

\author{
Inese Z. Bertyns, Avinoam Kowarsi, Dennis W. Shermeta, Robert A. De Lemos \\ and Claude J. MigeoN ${ }^{[28]}$ \\ The Harriet Lane Service of The Children's Medical and Surgical Center, \\ The Johns Hopkins Hospital and University, Baltimore, Maryland, USA
}

\section{Extract}

Three pregnant ewes and their fetuses, in utero, were infused constantly with ${ }^{14} \mathrm{C}$-cortisol and ${ }^{3} \mathrm{H}$-cortisol. The maternal concentrations of cortisol in plasma were $5.24 \pm 1.16 \mu \mathrm{g} / 100 \mathrm{ml}$ and the fetal concentrations in plasma were $2.39 \pm 0.25 \mu \mathrm{g} / 100 \mathrm{ml}$. Metabolic clearance rates were estimated to have a mean of 1,397 liters $/ 24 \mathrm{~h}$ in the ewes and 92 liters $/ 24 \mathrm{~h}$ in the fetuses. The mean rates of blood production for the ewe and the fetus were 73.6 and $2.14 \mathrm{mg} / 24 \mathrm{~h}$, respectively, while the mean rates of cortisol secretion for the ewe and fetus were 73.5 and $1.64 \mathrm{mg} / 24 \mathrm{~h}$, respectively. Application of the theoretical model presented, allowed us to calculate the contribution the mother was making to the cortisol concentration in the plasma of the fetus and vice versa. We also calculated the ratio of relative resistance for transplacental passage of cortisol.

\section{Speculation}

From the model proposed, it was calculated that the fetus contributed very little to the maternal cortisol levels. In two experiments, more than $60 \%$ of the fetal levels of plasma cortisol were of fetal origin, while in another experiment, almost all the cortisol was produced by the fetus. We speculate, therefore, that a 'placental barrier' exists in sheep during pregnancy. The physiological role of this barrier remains to be determined.

\section{Introduction}

The question of fetal participation in the production of hormones, and of the transplacental passage of these hormones, is of great theoretical and practical interest. A complex interrelation exists among the various compartments of the maternal-placental-fetal unit. GuRPIDE and VAN DE Wrele [6] have described a general method for the measurement of secretion rates of hormones in pregnant animals and their fetuses. These authors, however, did not calculate the degree of transplacental diffusion resistance to the passage of hormones from the mother to the fetus and vice versa. LigGins [8] demonstrated that intraperitoneal injection of $50 \mu \mathrm{g}$ dexamethasone $/ 24 \mathrm{~h}$ in near-term fetal lambs in utero produced parturition, whereas $10,000 \mu \mathrm{g}$ dexamethasone/24 $\mathrm{h}$ had no effect when given to the mothers. In another study [9], ACTH was given to the fetal lamb and when the fetal adrenal gland reached a size comparable to that of the normal newborn lamb, in about 5-7 days, labor occurred in the mother. These data suggested the existence of at least a partial 'placental barrier' to the transfer of adrenal steroids, and also, that the adrenal glands of the fetus play an important role in the initiation of labor $[5,10,11]$.

The experimental method used in this study permits estimation of the amount of diffusion resistance that occurs during passage of hormones across the placenta from the mother to the fetus and in the reverse direction. Measurements of maternal and fetal secretion rates of 
the hormones, their net transfer, and the contribution of the mother and her fetus to the plasma concentration of the hormones in both also were achieved with this method.

\section{Materials and Methods}

\section{Surgery}

Three ewes of the Dorset and Hampshire strain were used; each was about 120 days into pregnancy.

The animals were sedated, by intravenous injection, with $2.5 \%$ Surital, $1 \mathrm{ml} / 3 \mathrm{~kg}$, and placed in a supine position on the operating table. Anesthesia (Fluothane) was administered and controlled respiration maintained via endotracheal intubation. A subumbilical midline incision was made and carried through to the peritoneum after shearing and preparing the abdominal area. After palpation of fetus in utero, the fetal head was delivered and marsupialized to the margins of the uterotomy. The external jugular vein and common carotid artery were exposed and Silastic catheters were passed so that the arterial catheter was positioned and fixed in the aorta and the venous catheter in the right atrium. The catheters were secured to the fetus by means of a Dacron-enforced Silastic fixation plate fastened to the cervical fascia. The fetal head was returned to the uterus, the uterotomy was closed, and the peritoneum and fascial defect were repaired. The catheters were tunneled subcutaneously around to the maternal flank and exteriorized. Both catheters had been prepared with heparinized saline solution and now were connected to saline bottles to form a closed sterile system. Fetal status was evaluated at completion of surgery and at intervals thereafter by measuring fetal blood $\mathrm{pH}$ and $\mathrm{pCO}_{2}$.

Twenty-four hours later, at the time of the double constant infusion, the ewes had fully recovered and were standing and feeding in their stalls. A large-sized intravenous catheter was inserted percutaneously in the external jugular vein of the ewe and blood samples were obtained by separate venipunctures from the opposite jugular vein.

\section{Infusion}

Before starting the infusion, blood samples were obtained from the ewes and fetuses to measure the concentration of cortisol in plasma. Fetal $\mathrm{pH}$ and $\mathrm{pCO}_{2}$ were checked. In separate syringes, $30 \mu \mathrm{Ci}$ of $1,2-{ }^{3} \mathrm{H}-$ cortisol $\left({ }^{3} \mathrm{H}-\mathrm{F}\right)$ with a specific activity of $55.0 \mathrm{Ci} / \mathrm{mm}$ and $30 \mu \mathrm{Ci}$ of ${ }^{4-14} \mathrm{C}$-cortisol $\left({ }^{14} \mathrm{C}-\mathrm{F}\right)$ with a specific activity of $54.4 \mathrm{mCi} / \mathrm{mm}$ were diluted with $0.9 \%$ saline; the syringes were placed into two constant infusion pumps [24]. Two-minute collections of the radioactive materials were made and then each pump was run at a rapid speed to clear the dead space in the connecting tubing. The ${ }^{3} \mathrm{H}-\mathrm{F}$ was infused into the fetal arterial line at a rate of $5 \mathrm{ml} / \mathrm{h}$ for $3 \mathrm{~h}$, calculated to deliver $15 \mu \mathrm{Ci}$ (99 ng) of ${ }^{3} \mathrm{H}-\mathrm{F}$. At 2.75 and $3 \mathrm{~h}$ the infusion was stopped for $30 \mathrm{sec}$ and blood samples were withdrawn from the venous line located in the right fetal atrium. The ${ }^{14} \mathrm{C}-\mathrm{F}$ was infused into the maternal right jugular vein at a rate of $8.4 \mathrm{ml} / \mathrm{h}$, calculated to deliver $15 \mu \mathrm{Ci}(99.7 \mu \mathrm{g})$ in $3 \mathrm{~h}$. The amounts of ${ }^{3} \mathrm{H}-\mathrm{F}$ and ${ }^{14} \mathrm{C}-\mathrm{F}$ infused to mother and fetus were negligible in relation to their endogenous secretion rate. At $2 \mathrm{~h}$, and every $15 \mathrm{~min}$ thereafter, maternal blood samples were obtained from the left jugular vein. At the completion of the 3-h period, three 2-min collections were made, in separate vials, of both radioactive materials, and were used for calculations of infusion rates. Fetal $\mathrm{pH}$ and $\mathrm{pCO}_{2}$ were again checked and were normal in every case.

All three ewes delivered within the next 3 days. The weights of the fetuses were $2.5,2.35$, and $2.0 \mathrm{~kg}$, corresponding to maternal weights of 50,30 , and $55 \mathrm{~kg}$. Autopsies confirmed the location of the catheters in each fetus.

\section{Plasma Concentration of Cortisol}

Concentrations of cortisol in plasma of the ewe and fetus were determined by the protein binding method with the following modifications: a known amount of ${ }^{3} \mathrm{H}-\mathrm{F}$ was added to the plasma samples and after precipitation with ethanol and centrifugation, the supernatant was evaporated to dryness. The residue was applied to Whatman no. 2 paper (methanol washed) and chromatographed with benzene-methanol-water (2:1:1) for $5 \mathrm{~h}$ at $37^{\circ}$. The area opposite an external standard for cortisol was eluted. A small aliquot was taken for calculation of recovery of ${ }^{3} \mathrm{H}-\mathrm{F}$ and the remainder run through the protein binding method using $0.5 \%$ human plasma from pregnant women as a source for cortisol-binding globulin and activated Florisil for adsorption of unbound cortisol $[17,18]$.

\section{Plasma Concentration of Radioactive Cortisol}

Fifty micrograms of nonradioactive cortisol $(\mathrm{F})$ were added to each plasma sample. The plasma was extracted with chloroform and paper chromatography as described above was used. The losses were calculated by measuring the recovery of the nonradioactive $F$ by means of the PorTer-Silber reaction [21]. The radioactivity was measured in a liquid scintillation counter [25] as described by Rivarola et al. [22]. The preand postinfusion collections were similarly counted.

\section{Theoretical Model}

When radioactive cortisol is infused at a constant rate into the blood stream, the level of radioactivity 
gradually rises until a plateau is reached. At this time, the rate at which the radioactive cortisol is cleared from the blood is equal to the rate at which it is infused, and there is equilibrium in all body compartments.

During the constant infusion, when equilibrium is achieved, the specific activity of the cortisol in the blood pool is equal to the ratio of the rate of injection of radioactive cortisol to the rate of secretion of nonradioactive cortisol into the blood. As long as the constant infusion continues and equilibrium remains, all the cortisol crossing the placenta from the fetus into the ewe will have the specific activity reached by the cortisol secreted and originated in the fetus. It is thus possible to look at the cortisol secreted by the ewe and the fetus as two separate hormones, each having a different radioactive tag and specific activity, but interchanging between the two compartments.

The following abbreviations are used in the Calculation of Maternal and Fetal Secretion Rates: X, total concentration of hormone in maternal plasma; FM, concentration of the hormone in maternal plasma originating from the fetus; MM, concentration of the hormone in maternal plasma originating from the mother; $\mathrm{Y}$, total concentration of hormone in fetal plasma; $\mathrm{FF}$, concentration of the hormone in fetal plasma originating from the fetus; MF, concentration of the hormone in fetal plasma originating from the mother $;{ }^{14} \mathrm{C}$, rate of infusion of ${ }^{14} \mathrm{C}$ hormone into the mother (in cpm); ${ }^{3} \mathrm{H}$, rate of infusion of ${ }^{3} \mathrm{H}$ hormone into the fetus (in cpm); FSR, secretion rate of cortisol by the fetus; MSR, secretion rate of cortisol by the mother; ${ }^{3} \mathrm{HF}$, concentration of ${ }^{3} \mathrm{H}$-cortisol in fetal plasma at equilibrium (in $\mathrm{cpm}$ ) $;{ }^{14} \mathrm{CF}$, concentration of ${ }^{14} \mathrm{C}$-cortisol in fetal plasma at equilibrium (in $\mathrm{cpm}$ ); ${ }^{3} \mathrm{HM}$, concentration of ${ }^{3} \mathrm{H}$-cortisol in maternal plasma at equilibrium (in cpm); and ${ }^{14} \mathrm{CM}$, concentration of ${ }^{14} \mathrm{C}$ cortisol in maternal plasma at equilibrium (in $\mathrm{cpm}$ ).

Calculation of Maternal and Fetal Secretion Rates

At equilibrium, one can write:

$$
\begin{gathered}
\frac{{ }^{14} \mathrm{C}}{\mathrm{MSR}}=\frac{{ }^{14} \mathrm{CM}}{\mathrm{MM}}=\frac{{ }^{14} \mathrm{CF}}{\mathrm{MF}} \\
\frac{{ }^{3} \mathrm{H}}{\mathrm{FSR}}=\frac{{ }^{3} \mathrm{HM}}{\mathrm{FM}}=\frac{{ }^{3} \mathrm{HF}}{\mathrm{FF}} \\
\mathrm{FM}+\mathrm{MM}=\mathrm{X} \\
\mathrm{FF}+\mathrm{MF}=\mathrm{Y}
\end{gathered}
$$

Solving these four equations will give:

$$
\begin{gathered}
\mathrm{MM}=\frac{\left(\mathrm{Y} \cdot{ }^{3} \mathrm{HM} \cdot{ }^{14} \mathrm{CM}\right)-\left(\mathrm{X} \cdot{ }^{3} \mathrm{HF} \cdot{ }^{14} \mathrm{CM}\right)}{\left({ }^{3} \mathrm{HM} \cdot{ }^{14} \mathrm{CF}\right)-\left({ }^{3} \mathrm{HF} \cdot{ }^{14} \mathrm{CM}\right)} \\
\mathrm{FM}=\mathrm{X}-\mathrm{MM} \\
\mathrm{MF}={ }^{14} \mathrm{CF} \\
\mathrm{FF}=\mathrm{Y}-\mathrm{MF}
\end{gathered}
$$

$$
\begin{aligned}
\text { MSR } & =\frac{\frac{{ }^{3} \mathrm{HM}}{\mathrm{X}}-\frac{{ }^{3} \mathrm{HF}}{\mathrm{Y}}}{\left(\frac{{ }^{3} \mathrm{HM}}{\mathrm{X}} \cdot \frac{{ }^{14} \mathrm{CF}}{\mathrm{Y}}\right)-\left(\frac{{ }^{14} \mathrm{CM}}{\mathrm{X}} \cdot \frac{{ }^{3} \mathrm{HF}}{\mathrm{Y}}\right)} \cdot{ }^{14} \mathrm{C} \\
& =\frac{\left(\mathrm{Y} \cdot{ }^{3} \mathrm{HM}\right)-\left(\mathrm{X} \cdot{ }^{3} \mathrm{HF}\right)}{\left({ }^{3} \mathrm{HM} \cdot{ }^{14} \mathrm{CF}\right)-\left({ }^{14} \mathrm{CM} \cdot{ }^{3} \mathrm{HF}\right)} \cdot{ }^{14} \mathrm{C} \\
\mathrm{FSR} & =\frac{\frac{{ }^{14} \mathrm{CF}}{\mathrm{Y}}-\frac{{ }^{14} \mathrm{CM}}{\mathrm{X}}}{\left(\frac{{ }^{14} \mathrm{CF}}{\mathrm{Y}} \cdot \frac{{ }^{3} \mathrm{HM}}{\mathrm{X}}\right)-\left(\frac{{ }^{3} \mathrm{HF}}{\mathrm{Y}} \cdot \frac{{ }^{14} \mathrm{CM}}{\mathrm{X}}\right)} \cdot{ }^{3} \mathrm{H} \\
& =\frac{\left(\mathrm{X} \cdot{ }^{14} \mathrm{CF}\right)-\left(\mathrm{Y} \cdot{ }^{14} \mathrm{CM}\right)}{\left({ }^{3} \mathrm{HM} \cdot{ }^{14} \mathrm{CF}\right)-\left({ }^{14} \mathrm{CM} \cdot{ }^{3} \mathrm{HF}\right)} \cdot{ }^{3} \mathrm{H}
\end{aligned}
$$

Calculation of Metabolic Clearance Rates and Blood Production

The metabolic clearance rate (MCR) is calculated as the ratio of the rate of infusion of the radioactive hormone to its plasma concentration. The blood production rate of the hormone is the product of the metabolic clearance rate and the plasma concentration of the nonradioactive hormone.

\section{Calculation of the Net Transfer Rates}

This is calculated as the difference between blood production rate and secretion rate as defined above, and will be abbreviated to $V_{F M}$ for the transfer from fetus to mother and to $V_{M F}$ for that of mother to fetus (fig. 1). They are expressed in milligrams per $24 \mathrm{~h}$.

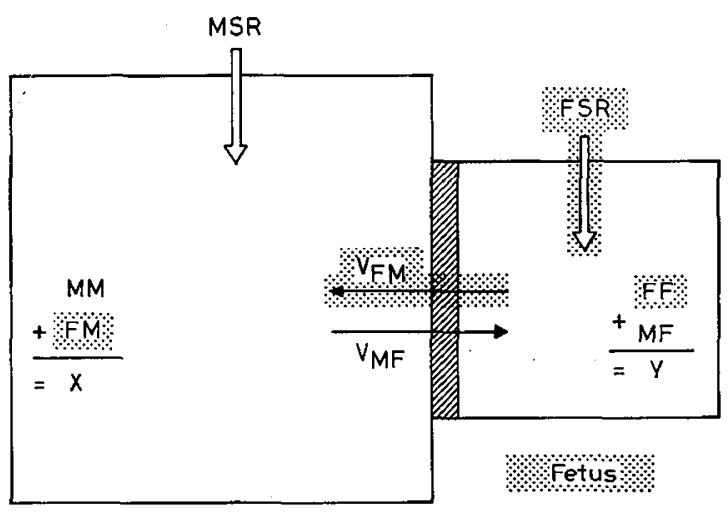

Mother

Fig. 1. Theoretical model of hormonal interrelations. Represented are the maternal secretion rate (MSR), fetal secretion rate (FSR) as well as the total maternal concentration $(\mathrm{X})$, which consists of the maternal hormone secreted by the mother (MM) and the fetal component that has crossed the placenta (FM). Similarly, in the fetus, the hormone of fetal origin (FF) together with that of maternal origin (MF) constitutes the fetal hormonal concentration $(\mathrm{Y})$. The net transfer rate from fetus to mother is $V_{F M}$ and from mother to fetus is $V_{M F}$. 


\section{Relative Diffusion Resistance}

In the sheep, there is no significant amount of cortisol-binding globulin [12], and therefore, all cortisol on both sides of the placenta is available for diffusion. If the passage of cortisol from one side of the placenta is concentration dependent, and therefore obeys the diffusion formula, then the resistance to the passage of the maternal hormone across the placental barrier to the fetal side will be defined as:

$$
\frac{M M-M F}{V_{M F}}
$$

The resistance to passage of the fetal hormone in the reverse direction will then be:

$$
\frac{F F-F M}{V_{F M}}
$$

The relative resistance could then be defined as the ratio between the two:

$$
\frac{(\mathrm{MM}-\mathrm{MF}) \cdot \mathrm{V}_{\mathrm{FM}}}{(\mathrm{FF}-\mathrm{FM}) \cdot \mathrm{V}_{\mathrm{MF}}}
$$

A ratio of greater than 1, indicates a greater resistance to the passage of cortisol from the mother to the fetus than from the fetus to the mother.

\section{Results and Discussion}

Concentrations of plasma, rates of metabolic clearance, of blood production, and of secretion, and net transfers of cortisol are presented in table I.

Measurement of Concentrations of Cortisol in Plasma of Sheep

The determination of cortisol concentrations in plasma of sheep has been difficult in the past and the results controversial $[1-4,7,12,13,19,20,23]$. All previous methods required large quantities of plasma and made measurements in utero impracticable. Also, under physiologic conditions, levels of cortisol are low in sheep when compared with man. This could be related to the low percentage binding of this steroid to plasma proteins of the sheep $(39 \pm 5 \%$ at room temperature), compared with over $90 \%$ in man. There was no significant increase in cortisol concentration or binding power in the pregnant ewe [12]. Our results for plasma concentration of cortisol agreed with those of LINDNER [12] who found levels of 1.7-3.5 $\mu \mathrm{g} /$ $100 \mathrm{ml}$ in stressed animals and $2.4-7.5 \mu \mathrm{g} / 100 \mathrm{ml}$ following abdominal surgery. HARRIsON et al. [7] and PAterson [19] found similar values, whereas GHester Jones et al. [3] found $6 \mu \mathrm{g} / 100 \mathrm{ml}$ in the fetus but $665 \pm 161 \mu \mathrm{g} / 100 \mathrm{ml}$ in ewes. The high values were probably related to the use of nonspecific methods.
It is of interest that in all cases the fetal concentration of cortisol in plasma was about one-half that of the maternal concentration. This in itself appears to indicate some form of placental diffusion resistance.

\section{Rate of Blood Production and of Secretion of Cortisol}

During the $3 \mathrm{rd} \mathrm{h}$ of constant infusion, a plateau of radioactive cortisol was demonstrated in the maternal and fetal plasma, demonstrating that equilibrium had been attained. Our values for the metabolic clearance rate (MCR) of cortisol in sheep were higher than in man. Great variations in the values stated for cortisol secretion appear in the literature $[1,2,13]$, varying from $3.1 \mathrm{mg}$ [4] to $192 \mu \mathrm{g} / 24 \mathrm{~h} / \mathrm{kg}$ (or $184 \mathrm{mg} / 24 \mathrm{~h}$ for a $40-\mathrm{kg}$ sheep) [19]. In our experiments, the rates of blood production ranged from 67.56 to $83.34 \mathrm{mg} / 24 \mathrm{~h}$, and the secretion rates from 66.72 to $83.02 \mathrm{mg} / 24 \mathrm{~h}$. These values were much higher than those found in pregnant women [16]. This was probably related to the low plasma concentrations, the short half-life of cortisol [19], and the large MCR in the ewes. We have also been able to show that the fetus in utero secreted cortisol, and that the rates of blood production by the fetus were $2.19-2.08 \mathrm{mg} / 24 \mathrm{~h}$ and the secretion rates were $2.07-1.31 \mathrm{mg} / 24 \mathrm{~h}$. Thus, the fetus secreted only about one-fiftieth as much cortisol as the mother. Expressed per kilogram of body weight, the fetus secreted about one-half as much as the mother.

\section{Net Transfer of Cortisol}

In each case, there was a significant transplacental passage of fetal cortisol to the maternal side. In experiments 1 and 2, a maternal-to-fetal transfer also occurred, but in experiment 3 almost no transfer took place. In this experiment, the ewe was the largest and healthiest and delivered the lightest lamb $(2.0 \mathrm{~kg})$. Meschia $[14,15]$ has shown that placental permeability to urea increases with fetal weight; that a similar situation exists with cortisol might be postulated.

The relative diffusion resistance ratio, calculated in each case, is shown in table II. The fetus contributed very little to the total cortisol concentration of plasma in the ewe, even though $20-50 \%$ of the total amount of cortisol secreted by the fetus crossed into the maternal circulation. At least $60 \%$ of the concentration of cortisol in plasma in the more mature fetuses (exps. 1 and 2) originated from their own adrenal glands, but in early pregnancy, as is presumed to be the case in experiment 3, almost all of the concentration of cortisol in plasma originated from the fetus. In this case, the relative resistance to hormonal crossover from maternal to fetal side was great. It must be noted that our values for relative resistance may be somewhat inaccurate since the method for their calculation included the sum of all the errors of the various variables. The value 
Table I. Concentrations of plasma and rates of metabolic clearance, blood production, secretion, and transfers $\left(V_{\mathrm{FM}}\right.$ and $\left.\mathrm{V}_{\mathrm{MF}}\right)$ of cortisol in the pregnant ewe and its fetus ${ }^{1}$

\begin{tabular}{|c|c|c|c|c|c|c|c|}
\hline \multicolumn{2}{|c|}{$\begin{array}{l}\text { Exp. } \\
\text { no. }\end{array}$} & $\begin{array}{l}\text { Plasma conc, } \\
\mu \mathrm{g} / 100 \mathrm{ml}\end{array}$ & $\begin{array}{l}\mathrm{MCR}^{2} \\
\text { liter } / 24 \mathrm{~h}\end{array}$ & $\begin{array}{c}\text { Blood production } \\
\text { rate, } \\
\mathrm{mg} / 24 \mathrm{~h}\end{array}$ & $\begin{array}{c}\text { Cortisol secretion } \\
\text { rate, } \\
\mathrm{mg} / 24 \mathrm{~h}\end{array}$ & $\begin{array}{l}\mathrm{V}_{\mathrm{FM}^{3}} \\
\mathrm{mg} / 24 \mathrm{~h}\end{array}$ & $\begin{array}{l}\mathrm{V}_{\mathrm{MF}}{ }^{3}, \\
\mathrm{mg} / 24 \mathrm{~h}\end{array}$ \\
\hline \multirow[t]{2}{*}{1} & Ewe & 4.00 & 1,689 & 67.56 & 66.72 & 0.74 & 0.63 \\
\hline & Fetus & 2.61 & 88 & 2.16 & 1.54 & & \\
\hline \multirow[t]{2}{*}{2} & Ewe & 6.28 & 1,327 & 83.34 & 83.02 & 0.32 & 0.88 \\
\hline & Fetus & 2.11 & 104 & 2.19 & 1.31 & & \\
\hline \multirow[t]{2}{*}{3} & Ewe & 5.50 & 1,274 & 70.07 & 69.66 & 0.41 & 0.01 \\
\hline & Fetus & 2.45 & 85 & 2.08 & 2.07 & & \\
\hline
\end{tabular}

1 All calculations were obtained by computerized programs. For each value two decimals are presented in the tables for the sake of the accuracy of the calculations; however, it is evident that these decimals have no biological significance.

${ }^{2} \mathrm{MCR}=$ metabolic clearance rate.

${ }^{3}$ Net transfer rates, calculated as difference between blood production rate and secretion rate: $\mathrm{V}_{\mathrm{FM}}=$ transfer from fetus to mother; $V_{M F}=$ transfer from mother to fetus.

Table II. Transplacental passage of cortisol and relative diffusion resistance ratios

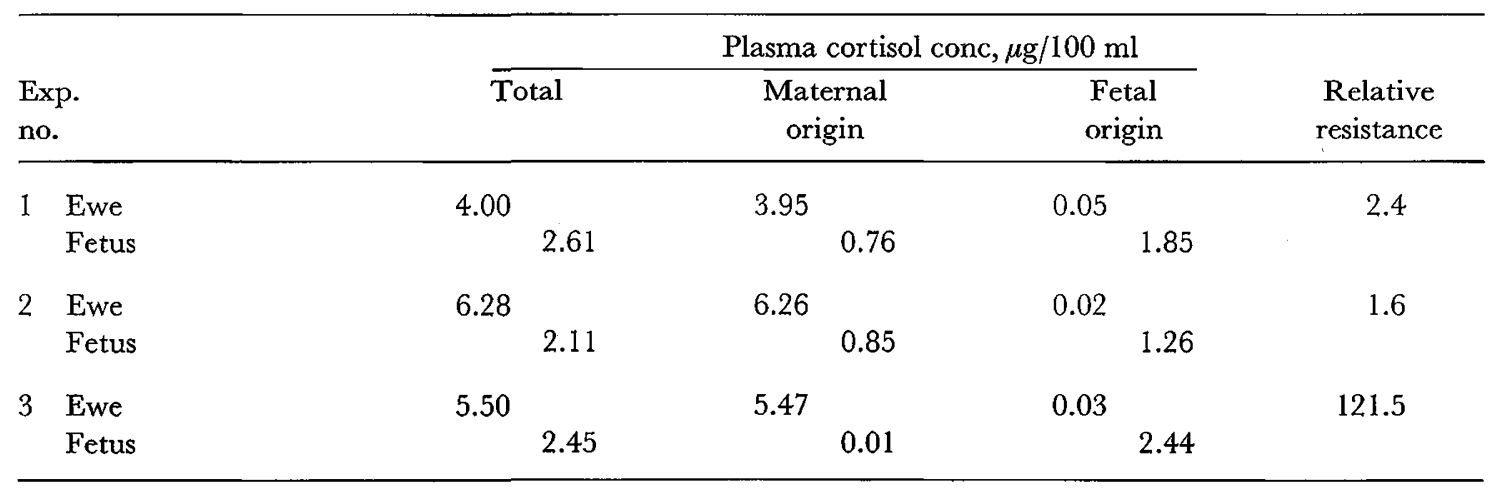

in experiment 3 might be particularly erroneous since the maternal contribution to the fetal cortisol concentration was almost nil. It can be speculated that the placental barrier serves to protect the fetus from the higher maternal hormonal levels.

\section{Summary}

A theoretical model that permits the calculation in the pregnant animal of a) maternal and fetal rates of 'blood production' of a hormone; $b$ ) net transfer rate across the placenta of the hormone in both directions; c) contribution of the mother to the fetal production and vice versa; and $d$ ) the ratio of the resistance to the passage across the placenta of the hormone of maternal origin and of the hormone of fetal origin is described.

An experiment is presented as an application of this model in which all these variables were measured in the pregnant sheep for cortisol. It was found that although a significant amount of the cortisol secreted by the fetus crosses unchanged to the maternal side, the placenta of the sheep presents a significant barrier for the movement of cortisol in the other direction. This barrier enables the fetus to maintain a lower concentration of cortisol than its mother, and thus to maintain an independent homeostatic regulation of its level. 


\section{References and Notes}

1. Alexander, D.P. ; Britron, H.G.; James, V.H.T.; Nixon, D. A.; Parker, R. A.; Wintour, E. M. and WRIGHT, R.D.: Steroid secretion by the adrenal gland of foetal and neonatal sheep. J. Endocrin. 40: 1 (1968).

2. Beaven, D.W.; Espiner, E.A. and Hart, D.S.: The suppression of cortisol secretion by steroids, and response to corticotrophins in sheep with adrenal transplants. J. Physiol., Lond. 171: 216 (1964).

3. Ghester Jones, I.; Jarrett, I.G.; Vinson, G.P. and PotTer, K.: Adrenocorticosteroid production of fetal sheep near term. J.Endocrin. 29: 211 (1964).

4. Coghlan, J.P.; Wintour, M. and Scoggins, B. A.: The measurement of corticosteroids in adrenal vein blood of sheep. Austr.J. exp. Biol.med. Sci. 44: 639 (1966).

5. Gowie, A.T.; Daniel, P.M.; Prtchard, M.M. and Tindal, J.S.: Hypophysectomy in pregnant goats and section of the pituitary stalk in pregnant goats and sheep. J. Endocrin. 28: 93 (1963).

6. Gurpide, E. and VAN DE Wiele, R.: Estimation of rates of production and transfer of hormones in pregnancy; in: K. AdAmsons: Diagnosis and treatment of fetal disorders, p. 113 (Springer, New York 1968).

7. Harrison, F.A.; MaDonald, I.R. and Paterson, J.Y.F. : Comparison of the apparent rate of cortisol turnover determined by isotope dilution and cortisol secretion rate. J. Endocrin. 28: 173 (1964).

8. Liggins, G.C.: Personal communication of unpublished data.

9. Liggrns, G. C.: Premature parturition after infusion of corticotrophins or cortisol into foetal lamb. J. Endocrin. 42: 323 (1968).

10. Liggins, G.C.; Holm, L.W. and Kennedy, P.C.: Prolonged pregnancy following surgical lesions of the foetal lamb pituitary. J. Reprod. Fertil. 12: 419 (1966).

11. Liggins, G. C. and Kennedy, P.C.: Effects of electrocoagulation of the foetal lamb hypophysis on growth and development. J. Endocrin. 40: 371 (1968).

12. Lindner, H.R.: Comparative aspects of cortisol transport: Lack of firm binding to plasma protein. J. Endocrin. 28: 301 (1964).

13. MaDonald, I.R. and Reich, M.: Corticosteroid secretion by the autotransplanted adrenal gland of the conscious sheep. J. Physiol., Lond. 147: 33 (1959).
14. Meschia, G.; Battaglia, F.C. and Burns, P.D.: Theoretical and experimental study of transplacental diffusion. J.appl.Physiol. 22: 1171 (1967).

15. Meschia, G.; Breathnach, C. S.; Cotter, J.R.; Hellegers, A. and Barron, D.H.: The diffusibility of urea across sheep placenta in the last two months of gestation. Quart.J.exp.Physiol. 50: 23 (1965).

16. Migeon, G.J.; KenNy, F.M. and TAYlor, F.H.: Cortisol production rate. VIII. Pregnancy. J. clin. Endocrin. 28: 661 (1968).

17. Murphy, B.E.P.: Application of the property of protein binding to the assay of minute quantities of hormones and other substances. Nature, Lond. 4920: 679 (1964).

18. Murphy, B.E.P.: Some studies of the proteinbinding of steroids and their application to the routine micro and ultramicro measurements of various steroids in body fluids by competitive protein-binding radioassay. J.clin. Endocrin. 27: 973 (1967).

19. Paterson, J.Y.F.: The turnover of cortisol in sheep. Biochem.J. 86: 1 (1963).

20. Paterson, J.Y.F.: The distribution and turnover of cortisol in sheep. J. Endocrin. 28: 183 (1964).

21. Porter, G. G. and Silber, R.H.: A quantitative color reaction for cortisone and related 17, 21dihydroxy-20 ketosteroids. J. biol. Ghem. 185: 201 (1950).

22. Rivarola, M.A.; Saez, J.M.; Meyer, W.J.; Jenkins, M.E. and Mrgeon, C. J.: Metabolic clearance rate and blood production rate of testosterone and androst-4-ene-3,17-dione under basal conditions, ACTH and HCG stimulation, comparison with urinary production rate of testosterone. J. clin. Endocrin. 26: 1208 (1966).

23. SABA, N.: The estimation of cortisol and cortisone in bovine and ovine plasma. J. Endocrin. 28: 139 (1964).

24. Harvard Apparatus Company, Inc., Millis, Mass.

25. Nuclear-Chicago Corporation, Des Plaines, IL.

26. The authors thank Miss Kathleen Scheller for her secretarial help.

27. Supported by Public Health Service Research Grants nos. AM-00180-18 and HD-00281-09, Traineeship Grant no.T1-AM-5219 and Research Career Award 5 K06 AM-21, 855 (CJM).

28. Requests for reprints should be addressed to: Glaude J. Migeon, M. D., CMSG 3-110, The Johns Hopkins Hospital, Baltimore, MD 21205 (USA). 29. Accepted for publication September 8, 1969. 